\title{
Pricing decision research for TPL considering different logistics service level influencing the market demand
}

\author{
Wei Li, Xuehui He, Kai Nie \\ College of Economics and Trade and Hunan Key Laboratory of Logistics Information and Simulation Technology, \\ Hunan University (China) \\ liweibncs@,hnu.edu.cn, xhbe@,bnu.edu.cn, knie@,hnu.edu.cn
}

Received: October 2012

Accepted: January 2013

\section{Abstract:}

Purpose: With the rapid development of economy and the support of government policy, the development of the logistics industry has become a new economic growth engine. As we all know, the reasonable price of logistics service is the most critical factor for logistics enterprises to win market share and make profit. At the same time, the service level is one of the most important factors which will influence the size of the market share. Therefore, this paper constructs a pricing model considering a situation that the logistics service level affects the market demand. This model helps the enterprises to make scientific decisions.

Methodology: To achieve this objective, this paper constructs the TPL service and the pricing decision models based on the game theory.

Findings: The conclusion shows that under the situation of independent decision-making, the enterprise which has strong ability of logistics service does not necessarily have a competitive advantage, while pricing equilibrium under the situation of joint decision-making, not only make both sides get more income, but also be conducive to improve the level of service.

Research limitations: In this research, there are some assumptions that might affect the accuracy the model such as there are only two TPL enterprises to participate in, and considerations are taken under the condition of complete information environment. These assumptions can be relaxed in the future work. 
Originality: In this research, logistics service level is taken account into the areas of logistics service pricing, which makes the models more practical and more perfect. And this paper constructs game models based on game theory to make up the limitations of traditional pricing theories in logistics service pricing.

Keywords: TPL, service level; service price, game theory

\section{Introduction}

The concept of Third Part Logistics (TPL) originated from 1980s and has developed into a certain size of industry in developed countries. Due to the emerging of TPL, the competition among TPL becomes fiercer. Intangible services usually have to face up to more uncertain market environment compared to tangible productions, and their market demand is not only influenced by price standard but also by service level. Boyer and Hult (2005) study showed that logistics service level can directly affect the demand of guests. Therefore, this paper assumes that the actual demand of the logistics service in this thesis is about the linear function of service price and the provided service level.

Some achievements of TPL research haven been made since 1980s. In summary, it can be divided into two aspects: first are the studies out the similarity of TPL

which is to elaborate TPL's concept, its importance and merits and flaws. For instance, Boyson (1999) believes that enterprises can reduce costs rapidly by delegating logistics business to the professional TPL service companies; Berglund (1998) believes that storage, process, transportation and other TPL services can achieve economy of scale, while TPL service can provide various types of service according to the diversified demands made by guests. Recently, while TPL enterprises become increasingly important, Chinese scholars begin to pay attention to TPL, and most of their studies are carried out from angle of TPL similarity. Second are studies on pricing TPL services. Lambert, Emmerlhainz and Gardner (1999) found that reasonable logistics service price is a key factor in a successful cooperation relationship; Albert and $\mathrm{Ha}$ (2004) analyzed how to make decisions on price and delivery to win the favor of the guests under the circumstances of competition and non-cooperation between two delivery service suppliers; Alberto and Giulio (2011) proved that maintenance cost of warehouses is correlated to the performance of the logistic service; Weijers, Glöckner and Pieters (2012) showed that sustainability is handled by the logistics company as an integral part of the corporate strategy. Some Chinese scholars also studied TPL from that aspect: Qi, Jiang and Huo (2010) studied the pricing policies of competition and cooperation between TPL companies and the subordinate logistics company of port enterprises, and built the advanced Bertrand 
competition model in competitive relationship, equivalent in consultation and cooperation model and remedies cooperation model in cooperative relationship.

Most studies on the influences of service levels on the variation of market demands are carried out from the view of supply chain. For example, Xu, Yu and Zhang (2006) used game model to study the supply chain formed by one supplier and one retailer, and respectively explored the decisions made by suppliers and retailers on the base of different service providers; Wu and Dan (2008) used dynamic game model to study coordinated design of contracts between customer companies and TPL service providers in the situation that logistics service level can influence product demands of the consumer enterprises.

\section{Model Introduction}

Suppose there are two logistics enterprises supplying service in the market, namely logistics enterprise 1 and logistics enterprise 2. Suppose the actual demand of logistics service is related to its price and service level. The demand functions of two enterprises are as follow respectively:

$$
\begin{gathered}
D_{1}=a-p_{1}+\alpha p_{2}+H_{1} \\
D_{2}=a-p_{2}+\alpha p_{1}+H_{2}
\end{gathered}
$$

$\alpha$ is a alternative coefficient of price, $\alpha \in[0,1]$; Assume that the potential market demand scale of two logistics enterprises (the price and service level are considered) is equal to $a$.

Assume that the relationship between the cost of logistics service and logistics service level is a strictly increasing convex function, the relationships between service costs $C_{i}$ and service level $H_{i}$ are as follow: firstly, the cost of services will raise as the service level increase, and the marginal costs will increase too; secondly, the stronger service ability provided, the smaller the marginal cost is. Set the relationship of service level and the service cost is: $C_{i}=k H_{i}^{2} / 2$, $\forall i \in\{1,2\} k_{i}$ is a related coefficient of logistics service provider, which reflect the ability of logistics enterprise, $k_{i}>\frac{1}{2}$. This second form of cost function is commonly used in the research (Xu et al., 2006; Xie \& Li, 2008). $\pi_{1}$ as the profit of Logistics enterprise 1 and $\pi_{2}$ as the profit of Logistics enterprise 2 , then, profit functions of two enterprises are as follow respectively:

$$
\begin{aligned}
& \pi_{1}=p_{1}\left(a-p_{1}+\alpha p_{2}+H_{1}\right)-\frac{1}{2} k_{1} H_{1}^{2} \\
& \pi_{2}=p_{2}\left(a-p_{2}+\alpha p_{1}+H_{2}\right)-\frac{1}{2} k_{2} H_{2}^{2}
\end{aligned}
$$




\section{Solution of Nash Game Under Independent Decision}

Assume that two logistics enterprise have equal status in the market, they conduct Nash game. In competitive relationship, two logistics enterprises make independent decision and determine its service price and service level respectively.

$$
\begin{gathered}
\frac{\partial \pi_{1}}{\partial p_{1}}=a-2 p_{1}+\alpha p_{2}+H_{1}=0 \\
\frac{\partial \pi_{1}}{\partial H_{1}}=p_{1}-k_{1} H_{1}=0 \\
\frac{\partial \pi_{2}}{\partial p_{2}}=a-2 p_{2}+\alpha p_{1}+H_{2}=0 \\
\frac{\partial \pi_{2}}{\partial H_{2}}=p_{2}-k_{2} H_{2}=0
\end{gathered}
$$

Solve the Nash equilibrium by above four formulas, and conclude that two logistics enterprises should adopt the pricing strategy and service level are as follow in order to pursue their maximum profit when under the completion relationship.

Conclusion 1: Conduct Nash game under independent decision, pricing and service level of two enterprises are such as below:

$$
\begin{aligned}
& p_{1}^{1}=\frac{a k_{1}\left[k_{2}(2+\alpha)-1\right]}{k_{1} k_{2}\left(4-\alpha^{2}\right)-2\left(k_{1}+k_{2}\right)+1} \\
& H_{1}^{1}=\frac{a\left[k_{2}(2+\alpha)-1\right]}{k_{1} k_{2}\left(4-\alpha^{2}\right)-2\left(k_{1}+k_{2}\right)+1} \\
& p_{2}^{1}=\frac{a k_{2}\left[k_{1}(2+\alpha)-1\right]}{k_{1} k_{2}\left(4-\alpha^{2}\right)-2\left(k_{1}+k_{2}\right)+1} \\
& H_{2}^{1}=\frac{a\left[k_{1}(2+\alpha)-1\right]}{k_{1} k_{2}\left(4-\alpha^{2}\right)-2\left(k_{1}+k_{2}\right)+1}
\end{aligned}
$$

Then, their profits are: $\pi_{1}^{1}=\frac{a^{2} k_{1}\left(2 k_{1}-1\right)\left[k_{2}(2+\alpha)-1\right]^{2}}{2\left[k_{1} k_{2}\left(4-\alpha^{2}\right)-2\left(k_{1}+k_{2}\right)+1\right]^{2}}$

$$
\pi_{2}^{1}=\frac{a^{2} k_{2}\left(2 k_{2}-1\right)\left[k_{1}(2+\alpha)-1\right]^{2}}{2\left[k_{1} k_{2}\left(4-\alpha^{2}\right)-2\left(k_{1}+k_{2}\right)+1\right]^{2}}
$$

From the above conclusion 1 we can see: when conduct Nash game, their profit difference only caused by the different of the cost. As the two logistics enterprises are in the same authority. The relationship of optimal service level and potential market demand scale is a positive linear 
correlation, that is, when the potential market demand scale increases, two logistics enterprises' optimal service level will increase.

Deduction 1: $p_{1}$ and $p_{2}, \pi_{1}$ and $\pi_{2}$ are increase function with alternative coefficient $\alpha$ if $k_{1}, k_{2}$ are fixed. It shows that the greater the degree of substitution, the higher price level under Nash equilibrium when two logistics enterprises are in monopolistic competition. As $k_{1}, k_{2}$ are fixed, the competition between two enterprises is price, according to the Bertrand price competition model, the enterprises will compete to reduce their prices in order to have a bigger share of the market, so when the competition is fierce, that $\alpha$ is great, the two enterprises' original price will be higher. Only in this way, the enterprises will have a bigger price cut space under the equilibrium level.

Deduction2: $\Delta H=H_{1}-H_{2}=\frac{a(2+\alpha)\left(k_{2}-k_{1}\right)}{k_{1} k_{2}\left(4-\alpha^{2}\right)-2\left(k_{1}+k_{2}\right)+1}$ as the difference degree of service level that provided by two logistics enterprises, if $\alpha$ is fixed, when $\Delta \mathrm{H}$ is bigger, then, the difference of the equilibrium price $\Delta p=p_{1}-p_{2}=\frac{a\left(k_{2}-k_{1}\right)}{k_{1} k_{2}\left(4-\alpha^{2}\right)-2\left(k_{1}+k_{2}\right)+1}$ is bigger too. It shows that the service price and the service level are related, the higher service level is, the higher price is.

Deduction 3: (1) when $\alpha$ is fixed, if $k_{1}=k_{2}$, then, $p_{1}=p_{2}, H_{1}=H_{2}$ and $\pi_{1=} \pi_{2}$. It shows that the service price and service level will be the same if two enterprises have the same ability to provide service when conducting Nash game. In this case, profit level of two logistics enterprises are the same. (2) when $\alpha$ is fixed, if $k_{1}>k_{2}$, then, $p_{1}<p_{2}, H_{1}<H_{2}$, but profit level of two enterprises can not be determined. $k_{1} k_{2}$ reflects that the ability to provide service of enterprise 2 is stronger than that of enterprise 1 , so the service level and the service price are higher than that of enterprise 1 too. When two enterprise conduct Nash game under independent condition, although logistics enterprise 2 has advantages in service capability, but the higher service price makes the profit level not necessarily higher than logistics enterprise 1 that's the service ability is weaker, which is accord with the reality condition.

From the above we can see that: the enterprise which has a strong ability to provide service may not have the absolute competitive advantage when it is in a competition condition. The reason is that the enterprise which has a strong ability is not willing to focus its energy on enhancing the service level, but to get more market share by cutting the price to achieve its maximize profit purposes. Next, relation of two logistics enterprises are discussed when they are in cooperation condition and compose service union.

\section{Equilibrium Solution Under Joint Decision}

Suppose that two logistics enterprises cooperate and together form a service union, in order to achieve win-win objective, they do the behavior such as information sharing ,cost sharing etc.. 
Under this condition, the pricing decisions and service level are to maximize the total profits. The profit function of the whole system is:

$$
\pi=p_{1}\left(a-p_{1}+\alpha p_{2}+H_{1}\right)+p_{2}\left(a-p_{2}+\alpha p_{1}+H_{2}\right)-\frac{1}{2} k_{1} H_{1}^{2}-\frac{1}{2} k_{2} H_{2}^{2}
$$

Consider a first-order we can get:

$$
\begin{aligned}
& \frac{\partial \pi}{\partial p_{1}}=a-2 p_{1}+2 \alpha p_{2}+H_{1}=0 \\
& \frac{\partial \pi}{\partial H_{1}}=p_{1}-k_{1} H_{1}=0 \\
& \frac{\partial \pi}{\partial p_{2}}=a-2 p_{2}+2 \alpha p_{1}+H_{2}=0 \\
& \frac{\partial \pi}{\partial H_{2}}=p_{2}-k_{2} H_{2}=0
\end{aligned}
$$

By solving the above four formulas, conclude that two logistics enterprises should adopt the pricing strategy and service level below in order to maximize the total profit when under the cooperation relationship.

Conclusion 2: when doing joint decision, pricing and service level of two enterprises are below:

$$
\begin{aligned}
& p_{1}^{2}=\frac{a k_{1}\left[2 k_{2}(1+\alpha)-1\right]}{4 k_{1} k_{2}\left(1-\alpha^{2}\right)-2\left(k_{1}+k_{2}\right)+1} \\
& H_{1}^{2}=\frac{a\left[2 k_{2}(1+\alpha)-1\right]}{4 k_{1} k_{2}\left(1-\alpha^{2}\right)-2\left(k_{1}+k_{2}\right)+1} \\
& p_{2}^{2}=\frac{a k_{2}\left[2 k_{1}(1+\alpha)-1\right]}{4 k_{1} k_{2}\left(1-\alpha^{2}\right)-2\left(k_{1}+k_{2}\right)+1} \\
& H_{2}^{2}=\frac{a\left[2 k_{1}(1+\alpha)-1\right]}{4 k_{1} k_{2}\left(1-\alpha^{2}\right)-2\left(k_{1}+k_{2}\right)+1}
\end{aligned}
$$

Then, their total profits are: $\quad \pi=\frac{a^{2}\left[4 k_{1} k_{2}(1+\alpha)-\left(k_{1}+k_{2}\right)\right]}{2\left[4 k_{1} k_{2}\left(1-\alpha^{2}\right)-2\left(k_{1}+k_{2}\right)+1\right]}$

Comparing with conclusion 1 , we can get: $H_{1}{ }^{1}<H_{1}{ }^{2}, H_{2}{ }^{1}<H_{2}{ }^{2}, p_{1}{ }^{1}<p_{1}{ }^{2}, p_{2}{ }^{1}<p_{2}{ }^{2}$ and $\pi_{1}{ }^{1}+\pi_{2}{ }^{1}<\pi$, then can get the following deduction.

Deduction 4: (1) Comparing with independent decision, the total profits of joint decision are higher than that of independent decision. The following can be obtained: the efficiency of competition is lower than the efficiency of cooperating, both sides have the potential incentive 
to cooperate. (2) Comparing with independent decision, the service level and service price of joint decision are higher than that of independent decision. It shows that their goal is to maximize the total profits when both are under the cooperation relationship, there is no need to lower the price to get a bigger share of the market, instead by improving the service level. So the service level and the service price in the cooperation condition are higher than that in the competition condition.

\section{Example Analysis}

Assume the market demand function of logistics enterprise 1 is $D_{1}=10-p_{1}+0.5 p_{2}+H_{1}$, the market demand function of logistics enterprise 1 is $D_{2}=10-p_{2}+0.5 p_{1}+H_{2}$, command $k_{1}=2, k_{2}=1$. The related results in table 1 are as below.

\begin{tabular}{|l|r|r|r|}
\cline { 2 - 4 } \multicolumn{1}{c|}{} & Independent decision & comparison & Joint decision \\
\hline Service price of enterprise 1 & 12 & $<$ & 40 \\
\hline Service level of enterprise 1 & 6 & $<$ & 20 \\
\hline Service price of enterprise 2 & 16 & $<$ & 50 \\
\hline Service level of enterprise 2 & 16 & $<$ & 50 \\
\hline Profit of enterprise 1 & 108 & $<$ & 200 \\
\hline Profit of enterprise 2 & 128 & $<$ & 250 \\
\hline Total profits & 236 & $<$ & 450 \\
\hline
\end{tabular}

Table 1. Related results under independent decision and joint decision

From the table 1 we can see that the service level has improved when logistics enterprises are in joint decision, and the total profits are increased too. So a union between logistics enterprises, making a horizontal cooperative, not only can make the enterprise win more profits, but also can avoid the monopolistic competition among the industry, which make enterprises intend to improve the logistics service level, and promote the healthy development of whole logistics market. We know that variable $k_{1}, k_{2}$ change will affect the total profit, as shown in figure1.

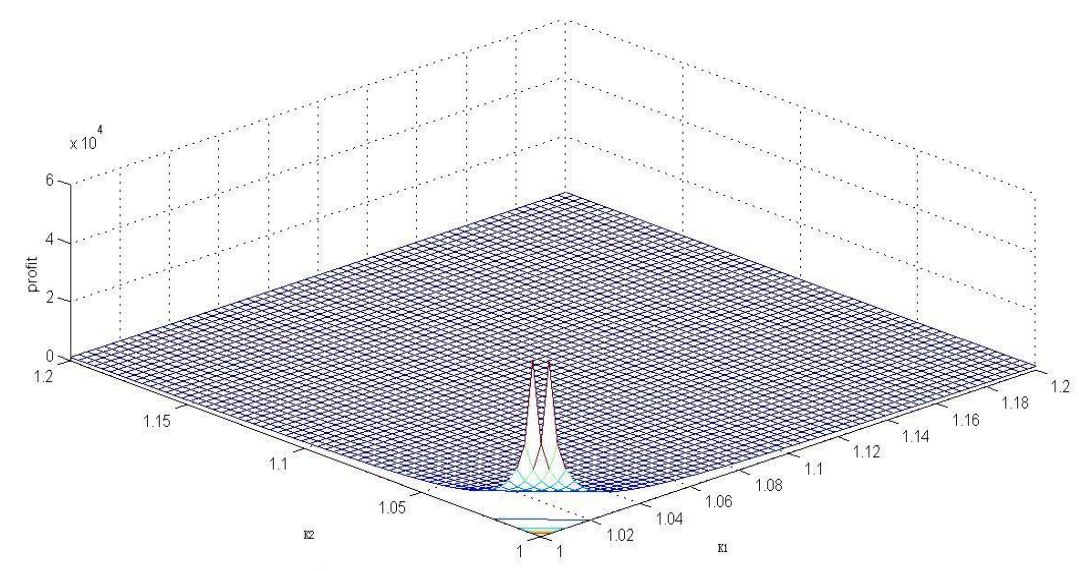

Figure 1 . The relationship between the variables $k_{1}, k_{2}$ and the total profit 


\section{Conclusion and Outlook}

Based on the service system consisted of two logistics enterprises, considering the situation that market demand is affected by the level of logistics service, this paper discusses the pricing strategies, the determination of the service level as well as coordination and cooperation strategy of two logistics enterprises in the independent decision and joint decision, and reach the following conclusions by constructing a game model.

(1) For monopolistic competition, two logistics enterprises in different logistics service level are inclining to maximize their own profit by price competition, rather than increasing the service level. (2) Enterprises with logistics services higher ability, do not have an absolute competitive advantage in their monopolistic competition, so there is no potential incentive for the enterprises striving to improve their service level which is not conducive to the development of the whole logistics market level. (3) The total profits of two logistics enterprises in joint decision are higher than the total profits earned by their own independent decision. The more competitive the logistics enterprises are, the more they should cooperate to determine the reasonable service level and reasonable pricing. This will not only increase the system's total profits, but also can make the choice of logistics services more flexible.

With the development of TPL enterprises, the scale of the logistics services market is becoming larger. The fact is there are much more than two logistics enterprises in one region, so extend the model by considering the reality can be an important direction for future research; at the same time, this paper aims to discuss the pricing and coordinating of logistics enterprises under complete information, but the logistics services market has become increasingly complex, asymmetric information is very often, therefore the pricing of logistics companies under incomplete information can be an important work for future research too.

\section{Acknowledgments}

This study was supported by general project of the ministry of education on humanities and social science research (11YJC790084), Research fund for the Doctoral Program of higher education (20110161120032) and philosophy social science fund of Hunan province (2010YBA048).

\section{References}

Albert, Y., \& Ha, L.L. (2004). Price and Delivery Logistics Competition in a Supply Chain. Review of Network Economics, 1355-1359.

Alberto, D.M., \& Giulio, M. (2011). Relationship between logistic service and maintenance costs of warehouses. Facilities, 411-421. 
Berglund, L.M. (1998). Third Party Logistics Providers-Towards a Conceptual Strategic Model. Linkoping Studies in Management and Economics, 456-467.

Boyer, K.K., \& Hult, G.T.M. (2005). Extending the supply chain: Integrating operations and marketing in the online grocery industry. Journal of Operations Management, 42, 661. http://dx.doi.org/10.1016/j.jom.2005.01.003

Boyson, C.D.R. (1999). Managing Effective Third party Logistics Relationships: What Does It Take. Journal of Business Logistics, 73-100.

Lambert, D.M., Emmerlhainz, M.A., \& Gardner, J.T. (1999). Building successful logistics partnerships. Journal of Business Logistics, 165-181.

Qi, E.S., Jiang, H., \& Huo, Y.F. (2010). Pricing analysis of logistics service between TPL and port enterprises. Journal of Tianjin university, 385-389.

Weijers, S., Glöckner, H., \& Pieters, R.(2012). Logistic service providers and sustainable physical distribution. Log Forum, 157-165.

Wu, Q., \& Dan, B. (2008). TPL coordination contract based on logistics service level influencing the market demand. Journal of management sciences in China, 64-74.

Xie, T.S., \& Li, J. (2008). Pricing game analysis for third-party logistics services. Journal of systems engineering, 751-757.

Xu, M.H., Yu, G., \& Zhang, H.Q. (2006). Game analysis on supply chain with providing service. Journal of management sciences in China, 18-26.

Journal of Industrial Engineering and Management, 2013 (www.jiem.org)

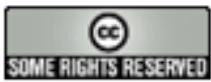

El artículo está con Reconocimiento-NoComercial 3.0 de Creative Commons. Puede copiarlo, distribuirlo y comunicarlo públicamente siempre que cite a su autor y a Intangible Capital. No lo utilice para fines comerciales. La licencia completa se puede consultar en http://creativecommons.org/licenses/by-nc/3.0/es/ 